Egyptian Journal of Aquatic Biology \& Fisheries

Zoology Department, Faculty of Science,

Ain Shams University, Cairo, Egypt.

ISSN $1110-6131$

Vol. 25(2): 1 - 19 (2021)

www.ejabf.journals.ekb.eg

\title{
Veratraldehyde as a food additive produced by the marine isolate Streptomyces diastaticus LC360811
}

\author{
Moustafa Y. El-Naggar ${ }^{1}$, Khouloud M. Barakat ${ }^{2}$, Mohamed A. Aly-Eldeen², \\ Hasnaa B. Ghoneim ${ }^{2}$ and Amira M. Hamdan ${ }^{3}$ ** \\ ${ }^{1}$ Botany and Microbiology Department, Faculty of Science, Alexandria University, Egypt. \\ ${ }^{2}$ National Institute of Oceanography \& Fisheries, NIOF, Egypt \\ ${ }^{3}$ Oceanography Department, Faculty of Science, Alexandria University, Alexandria, Egypt \\ *Corresponding Author: amira_hamdan1978@yahoo.com
}

ARTICLE INFO

\section{Article History:}

Received: Feb. 4, 2021

Accepted: Feb. 22, 2021

Online: March 8, 2021

Keywords:

Marine actinomycetes, S. diastaticus LC360811, Veratraldehyde, food additive,

Red Sea

\begin{abstract}
Twelve actinomycete isolates were derived from 6 sediment samples collected from the Red Sea coast, Egypt. The marine isolate, RS10, the most potent candidate, proved its capability to produce antimicrobial compound(s) that strongly inhibit both Gram-positive and Gram-negative bacteria. RS10 was identified by 16S rRNA gene sequencing as Streptomyces diastaticus LC360811. Culture supernatant of S. diastaticus LC360811 was extracted using n-butanol and tested against bacterial indicator strains using the disc diffusion method. The crude extract was partially purified using column chromatography and assessed for antimicrobial activity. Fraction no. 35 showed the highest antimicrobial activity against Acinatobacter sp. (34 mm), Pseudomonas aeruginosa ATCC 9027 (30 mm), Candida albicans (26 mm), Staphylococcus aureus ATCC 47077 (25 mm), Aeromonas hydrophila $(23 \mathrm{~mm})$, Streptococcus iniae $(22 \mathrm{~mm})$ and Borditella sp. $(18 \mathrm{~mm})$. This active fraction was then identified as veratraldehyde using spectroscopic techniques: GC-MS-MS and HPLC (diode array detector) and compared with the authentic reference. Veratraldehyde as a natural preservative proved to be a good candidate to preserve the flavor of juice, yoghurt and fermented milk and was able to control the growth of bacterial pathogens compared to the non-treated products till day fourteen.
\end{abstract}

\section{INTRODUCTION}

The discovery of new potent compounds and development of the currently known antibiotics are considered the most significant targets for competing the emerging pathogens in the $20^{\text {th }}$ century. Although many antibiotics have been commercialized to compete various pathogens, however, bacterial resistance is spreading throughout the world, revealing the steadily decreasing potencies of relevant antibiotics (Kaur et al., 
2015). Microorganisms, especially actinomycetes, are still the main source of natural products with pharmaceutical and agricultural importance (Hug et al., 2018).

Out of 22,500 well characterized biologically-active compounds reported in different sources, about $45 \%$ of them are produced only by actinomycetes (Rahman et al., 2011). The first report about mycelium-forming actinobacterium from the marine sediments was conducted several decades ago (Gebreyohannes et al., 2013). Recently, marine actinobacteria have been recognized as a source of novel antibiotics with unusual structures and properties, and have shown anticancer potential (Manivasagan et al., 2014).

Marine actinomycetes have been considered as the origin of the several novel bioactive compounds, for instance: rifamycin from Micromonospora, salinosporamide-A, an anticancer metabolite from Salinispora strain and marinomycins from Marinophilus sp. (Priyadarshini et al., 2016). In addition, abyssomicin-C is originated from Verrucosispora sp. and marinopyrroles from Streptomyces sp. (Mohseni et al., 2013) Streptomyces are largely isolated from soil and marine sediments (Tamreihao et al., 2016) and produce a large number of bioactive molecules with massive biosynthetic significance that remains unrivalled without a meaningful competitor among other microbial populations (Igbinosa et al., 2017).

Synthetic food additives may cause many diseases such as; allergies, hyperactivity, asthma, hay fever and certain reactions such as skin rash, vomiting, headache, tight chest, hives and worsening of eczema (Pandey $\boldsymbol{e t}$ al., 2012). Veratraldehyde is naturally found in ginger, peppermint, raspberry and many others. It has several pharmacological activities like antibacterial, antifungal and anti-stress properties (Kim et al., 2014; Prashant et al., 2014). Moreover, it is used in perfume manufacturing, food preservative and flavoring agent in food industries (Molleti \& Yadav, 2017) and are recorded as nonmutagenic compounds, non-carcinogenic and generally regarded as safe food additives (Braga et al., 2018).

The present study was presented to explore the capability of novel marine actinomycetes isolated from the Red Sea coast, Egypt, to produce bioactive compounds to be used as natural food additives. It is extended to report the optimal conditions for maximum production of the bioactive compound(s) by the marine Streptomyces diastaticus using Plackett-Burman and Box-Behnken statistical designs.

\section{MATERIALS AND METHODS}

\section{Sample collection and isolation}

Six samples of sea water and sediments were collected at $20 \mathrm{~cm}$ to $2 \mathrm{~m}$ depth from EL-Ahyaa beach and Hurghada on the Red Sea coast in Egypt. The samples were maintained at $4^{\circ} \mathrm{C}$ till transported to the laboratory for further analysis. The isolation process was carried out using pour plate technique (Subramani \& Aalbersberg, 2012). Starch casein agar medium (g/l; Casein powder, 1; Starch, 10; Agar, 20) was prepared 
using filtered sea water. Amoxicillin $(500 \mathrm{mg})$ and flucozole $(150 \mathrm{mg}$ ) were respectively added to the medium to minimize the bacterial and fungal contamination. Inoculated plates were incubated at $28-30^{\circ} \mathrm{C}$ for $7-15$ days. The selected actinomycete colonies were picked up and purified over starch casein agar medium (Amin et al., 2014).

\section{Tested bacteria}

Twelve bacterial indicator strains were kindly provided by Pharmaceutical Microbiology Lab, Faculty of Pharmacy, Alexandria University and the Microbiology Lab, National institute of Oceanography and Fisheries (NIOF), Egypt. These strains included five Gram-positive bacteria (Staphylococcus aureus ATCC 6538, Staphylococcus aureus ATCC 2923, Listeria monocytogenes ATCC 35152, Staphylococcus epidermis, Streptococcus iniae) and seven Gram negative-bacteria (Escherichia coli ATCC 8739, Klebseilla pneumonia ATCC 10031, Pseudomonas aeruginosa ATCC 9027, Acinetobacter baumannii, Bordetella pertussis, Aeromonas hydrophila, Pseudomonas aeruginosa) in addition to Candida albicans. Stock bacterial cultures were maintained on nutrient agar slants at $4^{\circ} \mathrm{C}$ with monthly transfer.

\section{Screening for antimicrobial activity}

In $250 \mathrm{ml}$ Erlenmeyer flasks, $100 \mathrm{ml}$ of ISP2 sea water medium (g/l: Yeast extract, 4; Malt extract, 10; Dextrose, 4) was inoculated with the purified actinomycete isolates and incubated under shaking condition at $30^{\circ} \mathrm{C}$ and $120 \mathrm{rpm}$ for 7 days. Fermented cultures were centrifuged at 6000rpm for 45 minutes to separate the fermented broth from the mycelial balls. The clear supernatant was filtered by bacterial membrane filter and used for activity assay.

Screening was carried out using cup plate method (Attimarad et al., 2012). Each well was loaded with $100 \mu$ of cell free actinomycete cultures and allowed to diffuse about 2 hours in the fridge, then incubated at $37^{\circ} \mathrm{C}$ for $24 \mathrm{hrs}$. After incubation, the zone of inhibition was measured and expressed in $\mathrm{mm}$ diameter. Based on the results, the potential actinobacterial strain was selected for morphological and molecular characterization (Thirumalairaj et al., 2015).

\section{Molecular Identification}

Genomic DNA was extracted from actinomycetes isolates according to protocol of GeneJet genomic DNA purification Kit (Thermo). Four $\mu 1$ from PCR mixture was loaded to examine the PCR product on $1 \%$ agarose gel against $1 \mathrm{~Kb}$ plus ladder (Fermentas). The primers used were as follows:

\section{F:- 5' AGA GTT TGA TCC TGG CTC AG 3'$$
\text { R:-3' GGT TAC CTT GTT ACG ACT T 5' }
$$

Finally, sequencing of the PCR product was carried out on GATC Company (Konstanz, Germany) by using DNA sequencer (ABI 3730XL, Germany). 


\section{Placket-Burman experimental design}

Optimization of medium components to maximize the production of the bioactive compound(s) by marine Streptomyces diastaticus was carried out using Plackett-Burman experimental design model. A set of 12 experiments was constructed for ten factors including the following parameters: (1) incubation time, (2) temperature, (3) $\mathrm{pH}$, (4) agitation rate, (5) volume of medium, (6) malt extract concentration, (7) yeast extract concentration, (8) dextrose concentration, (9) inoculum size, and (10) percentage of sea water. Each factor was tested at two levels (low and high), and statistical designs were expressed in coded values as -1 (low level) and +1 (high level). For -1 (low level) it was organised as follows: incubation time (7 days), temperature $\left(20^{\circ} \mathrm{C}\right), \mathrm{pH}(4)$, agitation rate $(90 \mathrm{rpm})$, volume of medium $(50 \mathrm{ml})$, malt extract concentration $(5 \mathrm{~g} / \mathrm{l})$, yeast extract concentration $(2 \mathrm{~g} / \mathrm{l})$, dextrose concentration $(2 \mathrm{~g} / \mathrm{l})$ and percentage of sea water $(0 \%)$. Whereas +1 (high level) was performed as follows: incubation time (17 days), temperature $\left(40^{\circ} \mathrm{C}\right), \mathrm{pH}(9)$, agitation rate $(180 \mathrm{rpm})$, volume of medium $(50 \mathrm{ml})$, malt extract concentration $(15 \mathrm{~g} / \mathrm{l})$, yeast extract concentration $(6 \mathrm{~g} / \mathrm{l})$, dextrose concentration $(8 \mathrm{~g} / \mathrm{l})$ and percentage of sea water $(50 \%)$ (Table 1). The production was carried out in triplicates, and the average value was taken (Rajendran et al., 2012). Statistical $t$-values for the two samples were calculated to determine the variable significance (Al-Sarrani \& El-Naggar, 2006).

Table 1. Plackett-Burman design for 10 variables and twelve trials

\begin{tabular}{c|c|c|c|c|c|c|c|c|c}
\hline Run & $\begin{array}{c}\text { Inoculum } \\
\text { size } \\
(\mathbf{m l})\end{array}$ & $\begin{array}{c}\text { Temp. } \\
\left({ }^{\circ} \mathbf{C}\right)\end{array}$ & $\begin{array}{c}\text { Initial } \\
\mathbf{p H}\end{array}$ & $\begin{array}{c}\text { Agitation } \\
\text { rate } \\
(\mathbf{r p m})\end{array}$ & $\begin{array}{c}\text { Volume of } \\
\text { medium }\end{array}$ & $\begin{array}{c}\text { Malt } \\
\text { extract } \\
\mathbf{c o n c .} \\
(\mathrm{g} / \mathbf{l})\end{array}$ & $\begin{array}{c}\text { Yeast } \\
\text { extract } \\
\mathbf{c o n c .} \\
(\mathrm{g} / \mathbf{l})\end{array}$ & $\begin{array}{c}\text { Incubation } \\
\text { time } \\
(\mathbf{h r})\end{array}$ & $\begin{array}{c}\text { Seawater } \\
(\%)\end{array}$ \\
\hline \hline $\mathbf{1}$ & + & + & - & + & + & + & - & - & - \\
\hline $\mathbf{2}$ & - & - & + & - & + & + & + & - & - \\
\hline $\mathbf{3}$ & - & - & - & + & - & + & + & + & - \\
\hline $\mathbf{4}$ & + & + & - & - & + & - & + & + & + \\
\hline $\mathbf{5}$ & - & - & + & - & - & + & - & + & + \\
\hline $\mathbf{6}$ & - & - & - & + & - & - & + & - & + \\
\hline $\mathbf{7}$ & - & - & - & - & + & - & - & + & - \\
\hline $\mathbf{8}$ & + & + & - & - & - & + & - & - & + \\
\hline $\mathbf{9}$ & + & + & + & - & - & - & + & - & - \\
\hline $\mathbf{1 0}$ & + & + & + & + & - & - & - & + & - \\
\hline $\mathbf{1 1}$ & - & - & + & + & + & - & - & - & + \\
\hline $\mathbf{1 2}$ & + & + & - & + & + & + & - & - & - \\
\hline
\end{tabular}

\section{Optimization of the production of bioactive components using Box-Behnken design}

Results of Plackett-Burman design showed that concentrations of yeast extract, malt extract and inoculum size are the three significant factors used to enhance the production of bioactive metabolite(s). The three components were studied at three different levels: 
low ( - ), high $(+)$ and base $(0)$. The experiment was carried out following Jose and Jebakumar (2013) in 15 trials with two replicates, and the response values were the mean of two replicates.

\section{Extraction of antimicrobial compounds using different solvents}

The potential actinomycete isolate was inoculated into ISP2 broth, and incubated at $20^{\circ} \mathrm{C}$ in a shaker at $180 \mathrm{rpm}$ for 17 days. Equal volume of various solvents (Petroleum ether, chloroform, ethyl acetate, n-butanol, ethanol, diethyl-ether and dichloromethane) was added separately to the culture supernatant to determine the best solvent for extraction. Crude extract, obtained from each solvent, was assessed for its activity against the tested bacteria using disc diffusion method. The antimicrobial activity was estimated by measuring the diameter of the inhibition zone after $24 \mathrm{hrs}$ of incubation at $37^{\circ} \mathrm{C}$ (Anuradha et al., 2014).

\section{Fermentation and preparation of crude n-butanol extract}

Based on solvent screening, Streptomyces diastaticus isolate was subjected to fermentation conditions and monitoring of the antimicrobial agent production at the end of the fermentation period. Twenty liters of ISP2 broth was inoculated with the 7 days old pre-culture of Streptomyces diastaticus isolate and incubated for 17 days at $20^{\circ} \mathrm{C}$ and 180 rpm. At the end of the incubation period, the culture supernatant was harvested by centrifugation at 8,000 $\mathrm{g}$ speed for $15 \mathrm{~min}$. The supernatant was extracted with equal volume of $n$-butanol $(1: 1 \mathrm{v} / \mathrm{v})$ and vaporized to dryness in a rotary evaporator at $40^{\circ} \mathrm{C}$. The crude extract was stored at $4^{\circ} \mathrm{C}$ for further studies (Arulappan et al., 2012).

\section{Thin layer chromatography (TLC)}

The n-Butanol crude extract was applied on silica gel sheets (Kieselgel 60, GF 254 of 0.25 thickness) with ethyl acetate: methanol: water $(88: 8: 3 \mathrm{v} / \mathrm{v})$ as solvent system according to Aadhimani et al. (2015) with some modifications to show different bands. The chromatogram was observed under ultraviolet (UV) light with short wave length 253 $\mathrm{nm}$ and long wave length $365 \mathrm{~nm}$. Furthermore, spray P-anisaldehyde - sulphuric acid reagent was used for preliminary colored compounds detection. Based on the separation of bands the $\mathrm{R}_{f}$ value was calculated (Wagner et al., 1984).

$\mathrm{R}_{f}$ value $=$ Distance travelled by solute $/$ Distance travelled by solvent

\section{Column chromatography}

Two grams of n-butanol crude extract were subjected to column chromatography using silica gel (100-200 mesh size, column $18 \mathrm{~mm} \times 300 \mathrm{~mm}$; Hi-media) packed and pre-equilibrated with petroleum ether. The column was first eluted with equilibration solvent i.e. petroleum ether (two bed volumes), followed by linear gradients of petroleum ether: ethyl acetate according to the method described by Shetty et al. (2014) with some modification, at a flow rate of $1 \mathrm{ml} / \mathrm{min}$. The eluent is passed through the column by gravity. Different fractions of $10 \mathrm{ml}$ each were collected and subjected to agar disc 
diffusion assay and thin layer chromatography. Petroleum ether: ethyl acetate (10:90 v/v) was used as screening system to develop the chromatograms which were observed under UV light (254 and $365 \mathrm{~nm}$ ). Similar TLC patterns with the same spot were mixed, and the solvent was evaporated on rotary evaporator. Thirty-five fractions were collected and screened against test microbes using disc diffusion assay.

\section{Characterization of the metabolites}

The fraction with the best antibacterial activity from column chromatography was further subjected to various spectroscopic analyses for characterization of the compound. Gas Chromatography Mass-Mass Spectrometry (GC-MS-MS) analysis was performed at the National Institute of Oceanography and Fisheries (NIOF), Alexandria, Egypt. GC-MS conditions were as follows: detector mass spectrometer voltage $70 \mathrm{eV}$, and its source temperature was $300^{\circ} \mathrm{C}$. The injection temperature was $240^{\circ} \mathrm{C}$, and the split mode was 0.5 $\mu \mathrm{l}$ injection. The HP 55\% dimethyl-95\% diphenyl polysiloxane non-polar column was performed with length of $30 \mathrm{~cm} \times 0.25 \mathrm{~mm}$ i.d., coating thickness film $0.25 \mu \mathrm{m}$. The oven was adjusted at $80^{\circ} \mathrm{C}$ for $1 \mathrm{~min}$, and the initial time was $1.5 \mathrm{~min}$ with $40^{\circ} \mathrm{C}$ which ended by a final temperature of $300^{\circ} \mathrm{C}$ and 4 min hold time, where the total run time was 15 min. The components were identified by comparing their retention times to those of authentic samples, as well as by comparing their mass spectra with those of Wiley 275 Library.

\section{High performance liquid chromatography (HPLC)}

HPLC was used for the identification and confirmation of the presence of veratraldehyde in the purified sample by comparing its chromatogram and its data (Retention time and the best wave length) with a standard using different wave lengths (260, 290 and $340 \mathrm{~nm}$ ) according to the procedure described by Tiossi et al. (2012).

\section{Comparison between the active fraction and some commercial antibiotics}

Five formulations of antibiotic-loaded discs were arranged according to their group: Aminoglycosides (Amikacin); Chloramphenicol (Chloramphenicol); Glycopeptides (Vancomycin); Quinolones (Ciprofloxacin) and Tetracycline (Tetracycline). They were used to compare their activities to the purified extract against the test organisms.

\section{Active fraction as food additive}

Pour plate method is usually the method of choice for counting the number of colony-forming bacteria present in a liquid specimen. Five $\mu 1 / \mathrm{ml}$ of purified compound was added to $10 \mathrm{ml}$ of fruit juice (pomegranate, banana, orange, and guava juice) and dairy products (fermented milk and yoghurt). The Standard Plate Count (SPC) was used to determine the total number of aerobic bacteria present in the juice and dairy product (Ismaili et al., 2016). Agar plates were incubated at $37^{\circ} \mathrm{C}$ for $24 \mathrm{hrs}$. Colonies were carefully counted and evaluated after $1^{\text {st }}, 3^{\text {rd }}, 7^{\text {th }}, 10^{\text {th }}$ and $14^{\text {th }}$ days of storage. 


\section{RESULTS}

\section{Screening for secondary metabolites}

Out of 12 marine actinomycetes strains, RS10 isolate strain collected from the sediments of Red Sea (Egypt) showed potential antibacterial activity against both Gram positive and Gram-negative bacteria, with average inhibition zone of $15.5 \mathrm{~mm}$ against Gram positive bacteria and $12.5 \mathrm{~mm}$ against Gram negative bacteria (Fig. 1).

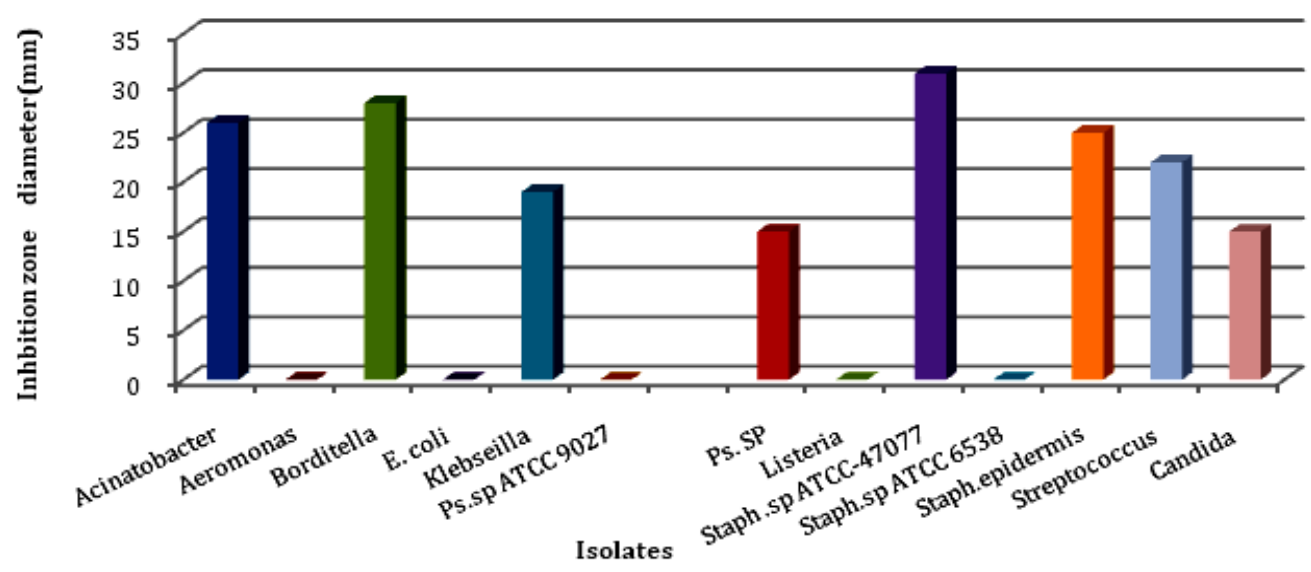

Fig. 1. Inhibition zone diameter of RS10 isolate against thirteen different isolates

\section{Molecular identifications of Red Sea isolate (RS10)}

The 16S rRNA gene sequences of RS10 isolate is compared to other sequences available in the NCBI database (Fig. 2). The sequence of RS10 isolate showed 97\% similarity to Streptomyces diastaticus and was deposited in the NCBI database with the accession numbers of LC360811.

\section{Plackett-Burman design}

The effect of 10 variables as inducers for bioactive compound production from LC360811 isolate showed that the optimum conditions for maximum production of the bioactive compound are recorded in Table (2). Malt extract exhibited positive effect on the production of the bioactive compound as compared with the rest of factors (Fig. 3). 


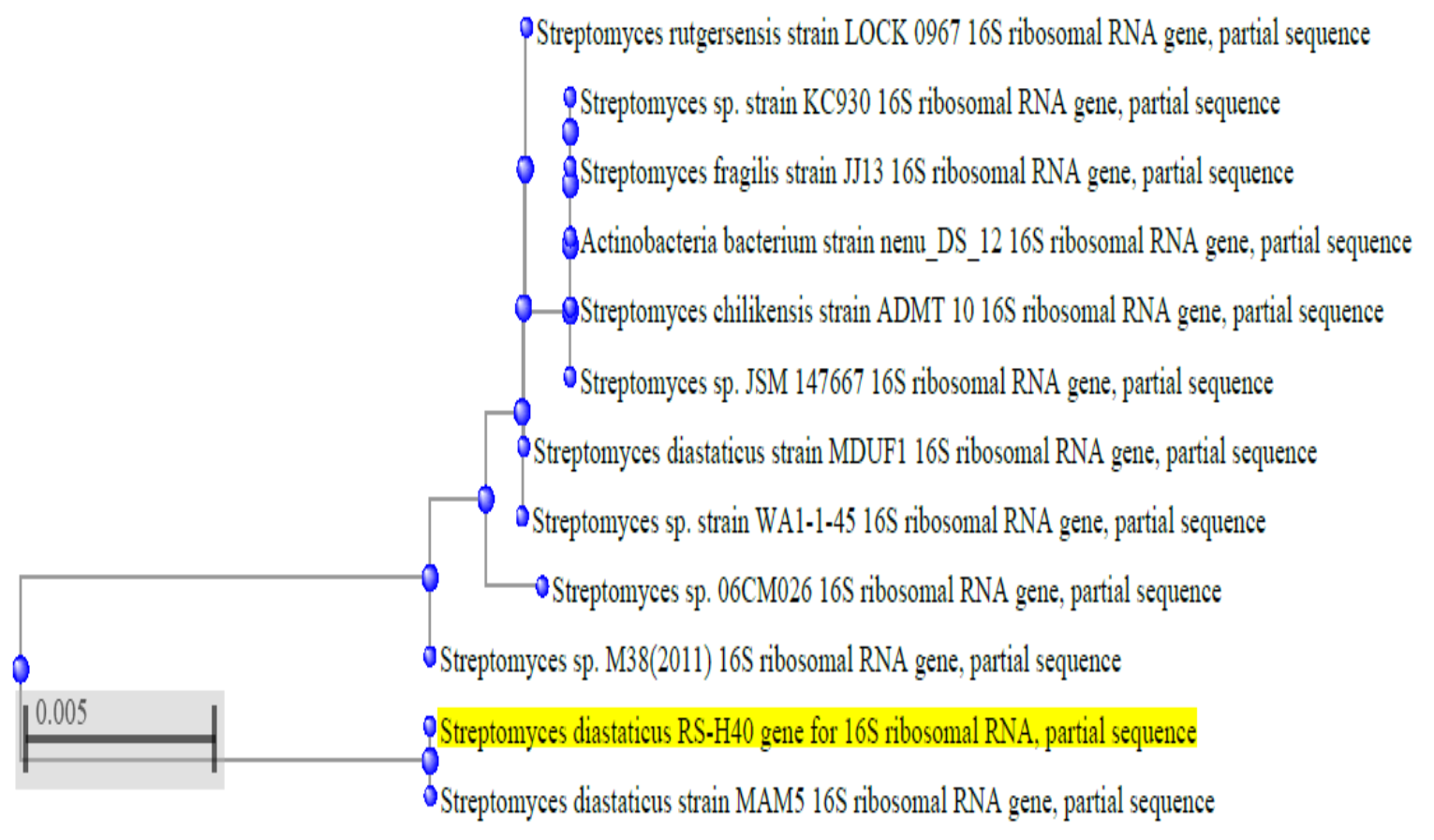

Fig. 2. Neighbor joining phylogenetic tree for the potential isolate RS10 identified as Streptomyces diastaticus with the closest NCBI (BLASTn) strains based on the 16S rRNA gene sequences.

Table 2. Statistical analysis of Plackett-Burman experimental statistical analysis of Plackett- Burman experimental results

\begin{tabular}{|c|c|c|}
\hline Variables & Main effect & $t$-value* \\
\hline Inoculum size & -19.54 & -1.57 \\
\hline temp & -1.94 & -0.14 \\
\hline pH & -18.2 & $\begin{array}{l}-1.44 \\
\end{array}$ \\
\hline Agitation rate & 2.28 & 0.16 \\
\hline Volume of medium & -7.42 & -0.54 \\
\hline Yeast extract & -19.36 & -1.55 \\
\hline Malt extract & 25.72 & 2.28 \\
\hline dextrose & -4.94 & -0.36 \\
\hline Incubation time & 1.54 & 0.11 \\
\hline Sea water & -8.9 & -0.65 \\
\hline
\end{tabular}

$* t-\alpha=0.1$ 


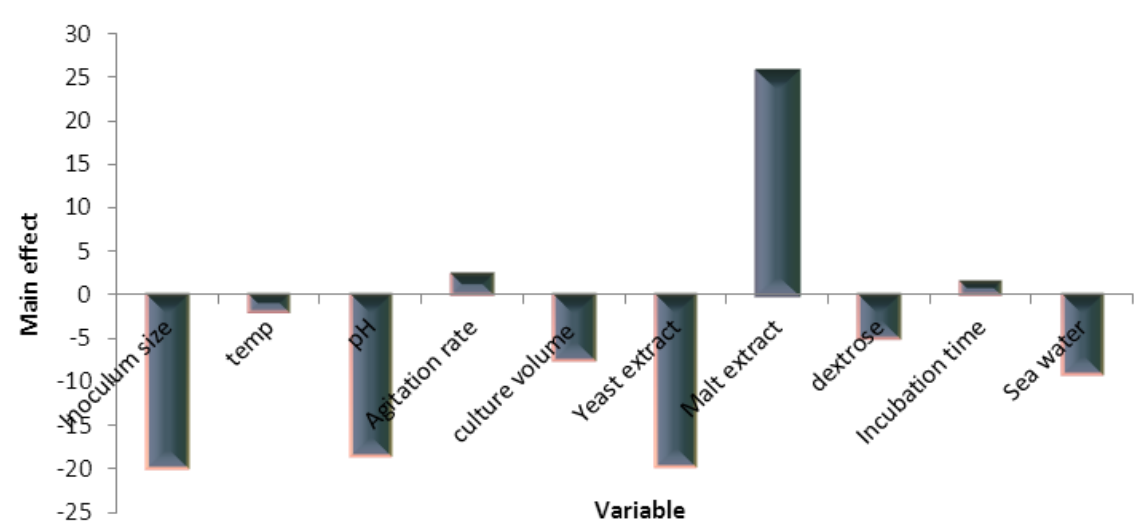

Fig. 3. Optimum condition using Placket-Burman design for maximum activity produced by LC360811 isolate.

Optimization of the antagonistic activity with the most effective factors using BoxBehnken Design

Box-Behnken experiment was applied for maximum bioactive compound productivity; where yeast extract, malt extract and inoculum size had the three significant factors $(P<0.05)$ that influenced the productivity of the antimicrobial compound(s) as shown in (Figure 4) and its regression equation was as follows:

$$
\begin{gathered}
Y=-12.8771+1.6052 \mathrm{X}_{1}+7.065 \mathrm{X}_{2}+1.12 \mathrm{X}_{3}-4.4875 \mathrm{X}_{1} \mathrm{X}_{1}+5.78947 \mathrm{X}_{1} \mathrm{X}_{2}+3.25 \mathrm{X}_{1} \\
\mathrm{X}_{3}+7.674 \mathrm{X}_{2} \mathrm{X}_{2}-1.11 \mathrm{X}_{2} \mathrm{X}_{3}-20.144 \mathrm{X}_{3} \mathrm{X}_{3}
\end{gathered}
$$

Where $\mathrm{Y}$ is the antagonistic activity and $\mathrm{X}_{1}, \mathrm{X}_{2}$ and $\mathrm{X}_{3}$ are the coded values of yeast extract, malt extract and inoculum size. The value of $R^{2}$ is 0.953 and the regression analysis model is highly significant as evident from the calculated $F$-value (8.11).
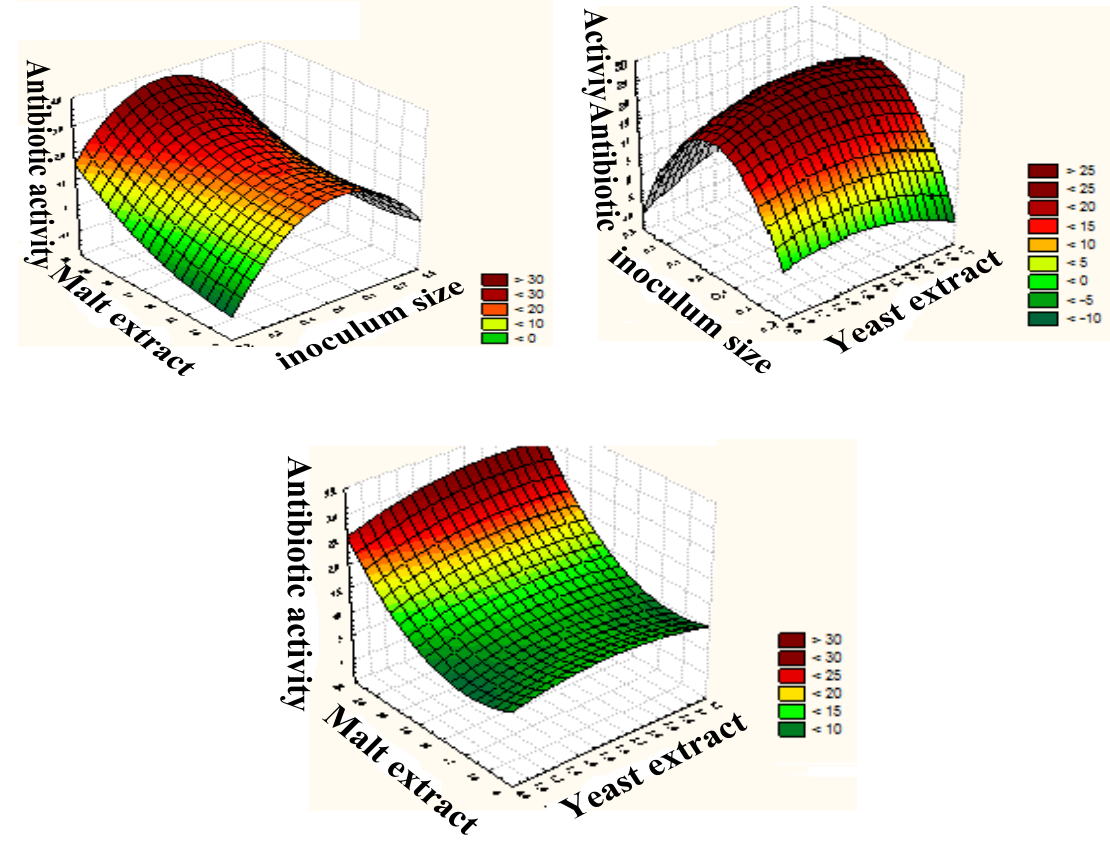

Fig. 4. Quadratic model of bioactive compound production from LC360811 isolate 


\section{Verification test of the model}

Factors from Box experiments were verified practically. Antibacterial activity measured against Streptococcus iniae was $38 \mathrm{~mm}$ for Streptomyces diastaticus LC360811. The optimal level of the variables for the production of antibacterial metabolites by Streptomyces diastaticus LC360811 was as follows: incubation time (18 days), inoculum size $(1.5 \mathrm{ml})$, yeast extract $(5 \mathrm{~g} / \mathrm{l})$, temperature $\left(20^{\circ} \mathrm{C}\right)$, agitation rate (180 rpm), malt extract (20 g/l), dextrose concentration (2 g/l), and initial pH (4)

\section{Extraction of antimicrobial compounds using different solvents}

Among the different solvents used for the extraction of the antimicrobial agents, $\mathrm{n}$ butanol seems to be the potent one as it exhibited the highest average inhibition zone (12 $\mathrm{mm}$ ) for all the tested bacteria. No inhibition zones was detected by dichloromethane or petroleum ether extracts. The secondary metabolites extracted by n-butanol showed different inhibitory activity against pathogenic bacteria, up to $20 \mathrm{~mm}$ with Acinatobacter sp. up to $17 \mathrm{~mm}$ with Staphylococcus aureus ATCC 47077, and no effect was detected on E. coli ATCC 8739 (Fig. 5).

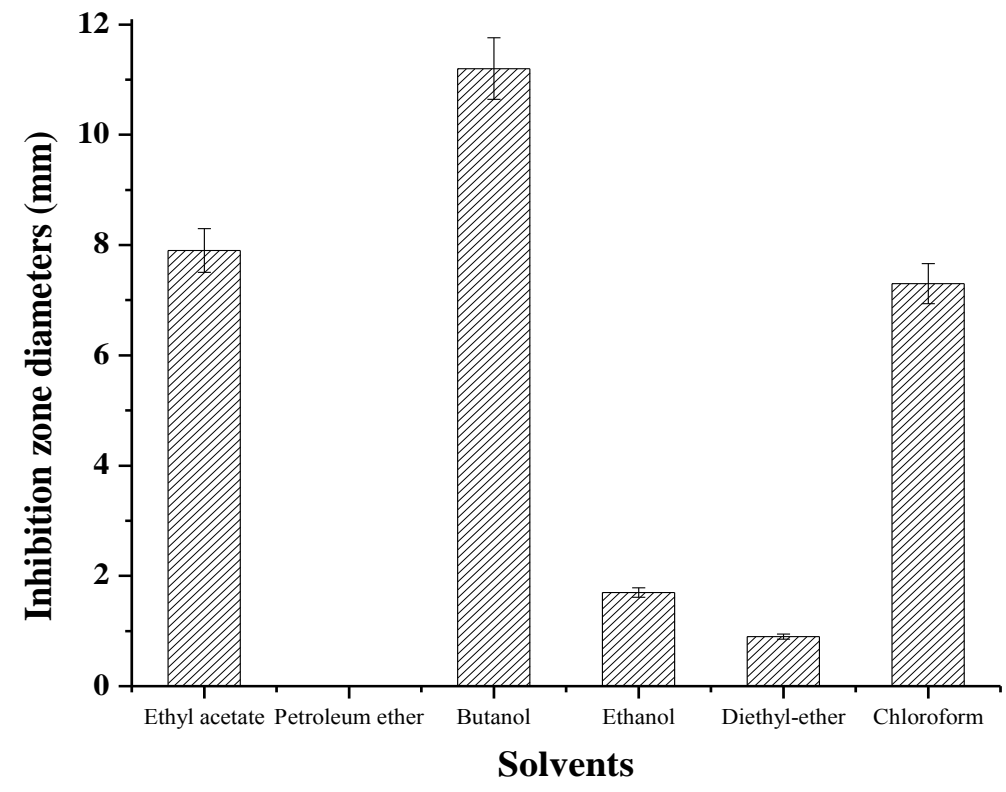

Fig. 5. Bioactivity of different organic solvents for the extraction of the bioactive compound(s) product by LC360811 strain. Bars are expressed as mean $\pm S E ; n=5$.

\section{Purification of the bioactive compound using column chromatography}

Out of 120 fractions, 35 sets of fractions were obtained from the column having different $\mathrm{R}_{f}$ values and antimicrobial activities against various pathogenic bacteria and yeast strains. Fraction number 35 showed the strongest antimicrobial activity and was further separated on TLC aluminum plates using the eluent system, hexane: dichloromethane: methanol (58:37:5) which succeeded to separate six different fractionated spots on TLC plate; only four spots were detected under UV light. All spots 
were visualized using p-anisaldhyde spray reagent (Table 3). Bioautography test of TLC plate was carried out using Acinetobacter sp. as a pathogen indicator where $\mathrm{R}_{f}$ value of 0.26 exhibited a promising antibacterial activity against the tested pathogen.

Table 3. Bioautography and $\mathrm{R}_{f}$ of the active fraction (no. 35) against Acinetobacter $s p$

\begin{tabular}{ccc}
\hline Fraction No. & $\mathbf{R}_{f}$ value & $\begin{array}{c}\text { Inhibition zone diameter } \\
(\mathbf{m m})\end{array}$ \\
\hline $\mathbf{1}$ & 0.07 & - \\
$\mathbf{2}$ & 0.26 & 26 \\
$\mathbf{3}$ & 0.32 & - \\
$\mathbf{4}$ & 0.68 & - \\
$\mathbf{5}$ & 0.91 & - \\
\hline
\end{tabular}

\section{Identification of bioactive compound using GC/MS-MS}

Fraction number 35 was evaporated to dryness. A pale yellow residue was obtained and dissolved in DMSO. This residue was analyzed by GC/MS technique. Veratraldehyde was identified at retention time 9.10 with an illustrated mass spectrum and chemical structure using MS-MS analysis (Fig. 6). Further purification on TLC was carried out to scratch the active compound.
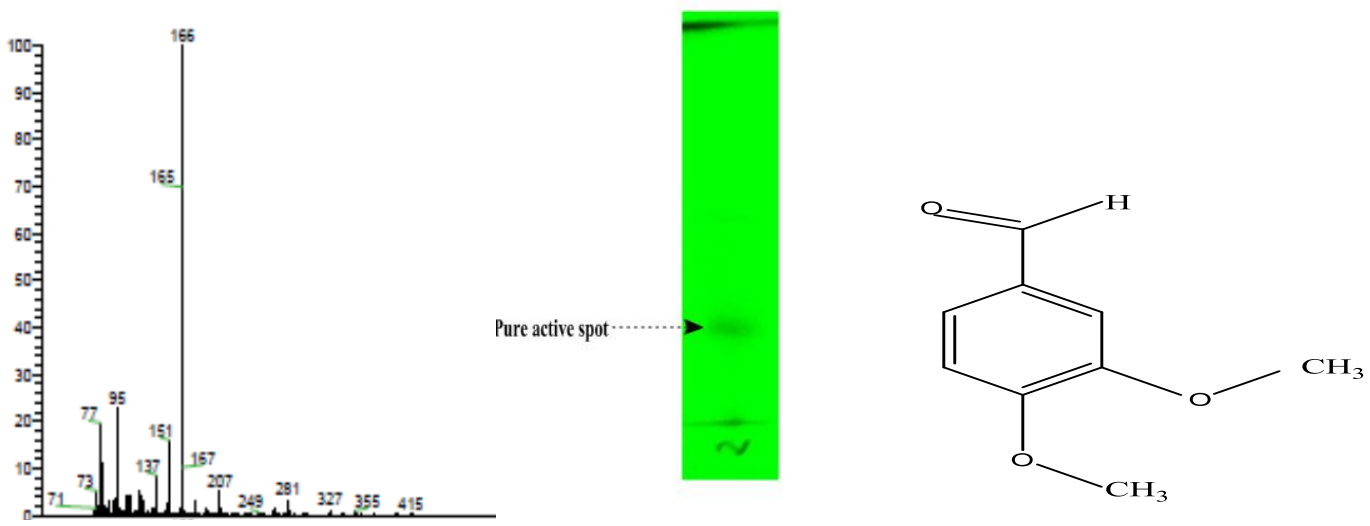

Fig. 6: Mass spectrum of bioactive n-butanol Veratraldehyde fraction (35) of Streptomyces diastaticus. Pure active spot under UV at $254 \mathrm{~nm}$

\section{Detection of Veratraldehyde using HPLC}

Standard veratraldehyde sample was detected at wavelengths 4.088, 4.062 and 4.92 nm. Similarly, the purified sample was approximately detected at the same retention times; 4.119, 4.069 and $4.89 \mathrm{~nm}$, as a confirmation that the sample purified from Streptomyces diastaticus isolated from the Red Sea was Veratraldehyde (Fig. 7). 

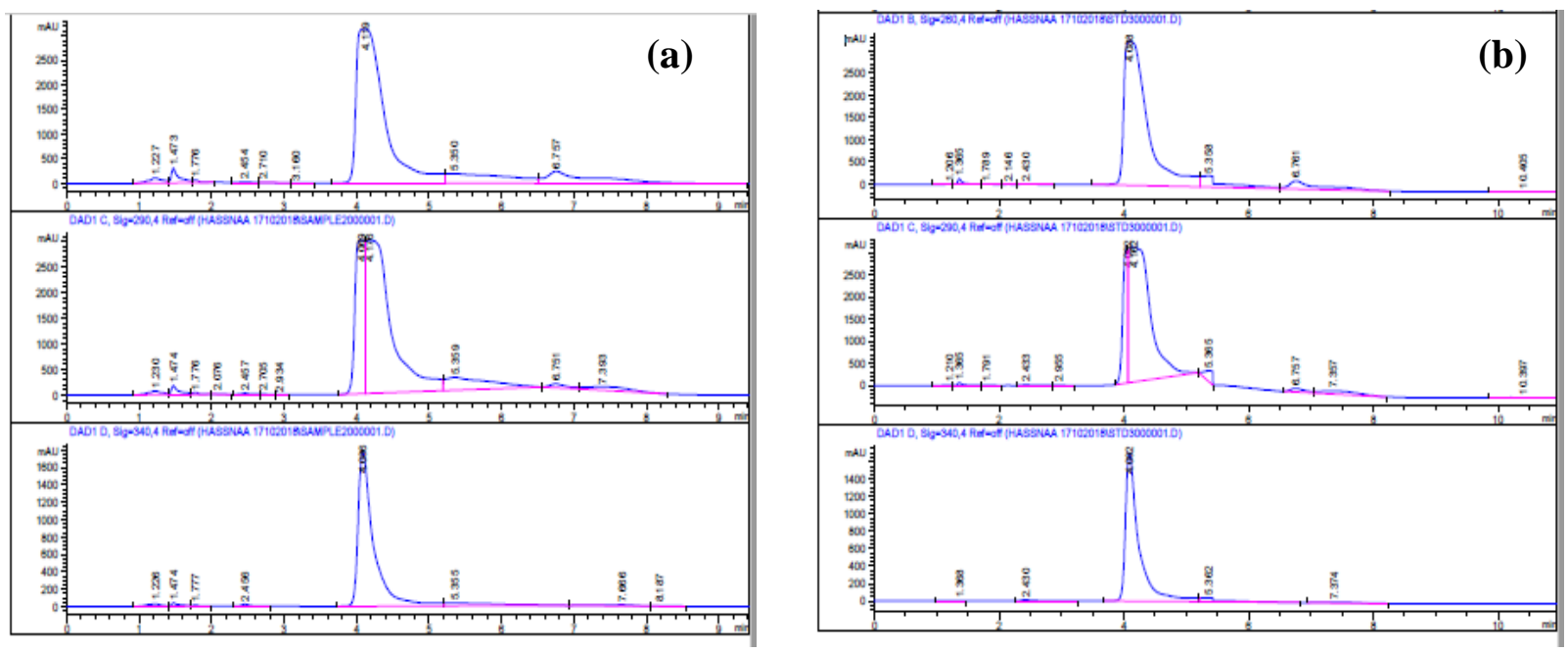

Fig. 7: HPLC chromatogram of purified Veratraldehyde (a) and its authentic sample (b) at three different wavelengths (260, 290 and $340 \mathrm{~nm})$.

\section{Comparison using some antibiotics}

Commercial antibiotics were used to compare the antagonistic activity with those obtained from the purified veratraldehyde of Streptomyces diastaticus. The highest average inhibition by commercial compounds against Gram negative bacteria $(28.6 \mathrm{~mm})$ was recorded with Ciprofloxacin, while the lowest activity $(9.4 \mathrm{~mm})$ was detected with Tertracycline. Meanwhile, the inhibition of purified veratraldehyde from Streptomyces diastaticus $(18.6 \mathrm{~mm})$ was approximately similar to that of amoxicillin/clavulanic (17.8 $\mathrm{mm}$ ). On the other hand, Ciprofloxacin caused the highest average inhibition grampositive bacteria $(32 \mathrm{~mm}$ ) against $12.8 \mathrm{~mm}$ caused by veratraldehyde (Table 4). Minimum inhibitory concentration values of the veratraldehyde from $S$. diastaticus LC360811 was $26 \mathrm{~mm}$ against $S$. iniae and $25 \mathrm{~mm}$ against $S$. aureus ATCC 47077.

Table 4. Comparison between different commercial antibiotics and purified veratraldehyde

\begin{tabular}{|c|c|c|c|c|c|c|c|c|c|c|c|c|}
\hline \multirow[b]{3}{*}{ Antibiotic } & \multirow[b]{3}{*}{ Code } & \multicolumn{11}{|c|}{ Inhibition zone diameter $(\mathrm{mm})$} \\
\hline & & \multicolumn{6}{|c|}{ Gram Negative } & \multicolumn{5}{|c|}{ Gram Positive } \\
\hline & & 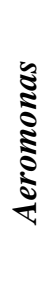 & 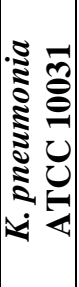 & 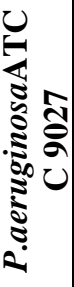 & 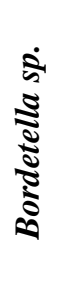 & 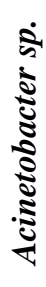 & 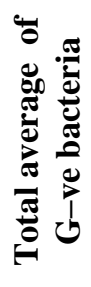 & 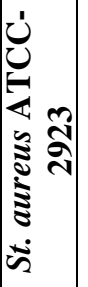 & 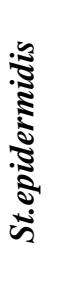 & 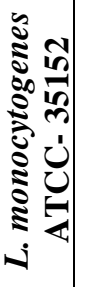 & 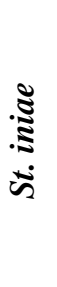 & 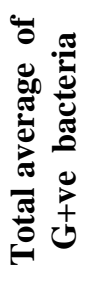 \\
\hline Amoxicillin/clavulanic & AUC & 16 & 25 & 19 & 29 & - & 17.8 & 22 & - & 24 & 9 & 13.75 \\
\hline Chloramphenicol & $\mathrm{C}$ & 35 & 20 & 14 & 37 & 20 & 25.2 & 40 & 22 & 20 & 26 & 27 \\
\hline Ciprofloxacin & CIP & 42 & 33 & 15 & 28 & 25 & 28.6 & 32 & 29 & 37 & 30 & 32 \\
\hline Erythromycin & $\mathrm{E}$ & 35 & 15 & 20 & 13 & 16 & 19.8 & 23 & - & 31 & 21 & 18.75 \\
\hline Tetracycline & TE & 21 & - & - & 18 & 8 & 9.4 & 11 & - & 31 & 21 & 15.75 \\
\hline \multicolumn{2}{|c|}{ Purified veratraldhyde isolated from St. diastaticus } & 22 & 20 & 30 & - & 38 & 18.4 & 25 & - & - & 26 & 12.8 \\
\hline
\end{tabular}

(- ) indicated that no inhibition zone was detected 


\section{Purified veratraldehyde as food additive}

The total bacterial count in all untreated samples with veratraldehyde increased gradually, attaining the maximum after 2 weeks with changing odor to offensive. Guava juice was fermented with the appearance of acid bubbles, while all the treated juice samples and dairy products maintained their fresh aspects and odor. In addition, the color of banana juice did not change in treated tubes, but it turned into brown color in untreated ones. On the $1^{\text {st }}$ day, the bacterial count in fruit juices, treated by Veratraldehyde, decreased about $90.5 \%$ and $88.7 \%$ in both pomegranate and orange juices, respectively, against $50 \%$ and $43 \%$ in banana and Guava juices, respectively. In the case of orange and banana juices, the preservative activity of the purified compound increased gradually with time reaching its maximum at the day 14 and kill about $90.9 \%$ and $81 \%$ of the total bacterial count in the two juices, respectively (Table 5). This activity decreased by the day 14 reaching only $11 \%$, and slightly increased in case of guava juice $(61.6 \%)$. In case of dairy products, fermented milk and yogurt, bacterial counts decreased after the $1^{\text {st }}$ day by about $85 \%$ and $67.6 \%$, respectively, whereas the reduction in bacterial count were $70.3 \%$ and $77.6 \%$, respectively, at day fourteen.

Table 5. Effect of the purified Veratraldehyde of LC360811 strain on the total bacterial count

\begin{tabular}{|c|c|c|c|c|c|c|c|c|c|c|c|c|}
\hline \multirow{3}{*}{ DAY } & \multicolumn{12}{|c|}{ CFU/ml for milk and Juice samples } \\
\hline & \multicolumn{2}{|c|}{ milk } & \multicolumn{2}{|c|}{ Yoghurt } & \multicolumn{2}{|c|}{$\begin{array}{c}\text { Pomegranate } \\
\text { juice }\end{array}$} & \multicolumn{2}{|c|}{ Guava juice } & \multicolumn{2}{|c|}{ Orange juice } & \multicolumn{2}{|c|}{ Banana juice } \\
\hline & untreated & $\mathrm{T}$ & untreated & $\mathrm{T}$ & untreated & $\mathrm{T}$ & untreated & $\mathrm{T}$ & untreated & $\mathrm{T}$ & untreated & $\mathrm{T}$ \\
\hline 1 & 20 & 3 & 34 & 11 & 53 & 5 & $>300$ & 150 & 71 & 8 & 223 & 127 \\
\hline 3 & 22 & 3 & 98 & 10 & $>300$ & 71 & $>300$ & 249 & 98 & 12 & $>300$ & 98 \\
\hline 7 & 24 & 5 & 244 & 44 & $>300$ & 143 & $>300$ & 112 & 174 & 110 & $>300$ & 77 \\
\hline 10 & 84 & 81 & $>300$ & 46 & $>300$ & 277 & $>300$ & 110 & 220 & 58 & $>300$ & 54 \\
\hline 14 & 54 & 16 & $>300$ & 67 & $>300$ & 267 & $>300$ & 115 & 253 & 23 & $>300$ & 57 \\
\hline
\end{tabular}

\section{DISCUSSION}

The incidence of multidrug resistant organisms is increasing and compromising the treatment of a growing number of infectious diseases. Therefore, there is an urgent need to develop new effective drugs against current antibiotic resistant pathogens (Abad $\boldsymbol{e t}$ al., 2011; El-Naggar et al., 2016, 2017; El-Moslamy et al., 2018).

The RS10 strain, isolated from Red sea sediment, showed positive activity against the tested microbes ranged from $10-30 \mathrm{~mm}$. Although the potent isolate showed morphological variations on the three used culture media, RS10 displayed the substantial growth in starch casein agar medium. These results agree with Gebreyohannes $\boldsymbol{e t}$ al. (2013) who attributed the excellent microbial growth of Streptomyces sp. in starch casein 
agar medium to sufficient amount of nutrients in this medium, successful isolation of different marine Streptomyces sp. was performed with different morphological aspects on starch nitrate media with gray mass spore without diffusible pigment in media (Ye et al., 2009; Al-Askar et al., 2014)

The present study revealed that $S$. diastaticus LC360811 was able to inhibit $S$. aureus ATCC 2923, and had no effect on either E. coli ATCC 8739 or P. aeruginosa ATCC 9027. Similarly, Hunadanamra et al. (2013) stated that $S$. diastaticus SMP3-1 isolate was able to inhibit $S$. aureus ATCC 6538, whereas it showed weak antagonistic effect on E. coli ATCC 25922 and P. aeruginosa ATCC 27853. Moreover, Subramanian et al. (2017) observed a broad antibacterial activity of Streptomyces carpaticus MK-01 against Gram positive bacteria.

Actinomycetes fermentation is a complex process; as it depends on its performance, fermentation medium, as well as the suitable environmental conditions (Singh et al., 2017) such as: inoculum size, $\mathrm{pH}$, incubation time, temperature and agitation rate. The statistical analysis of Plackett-Burman experimental results indicated significant value between malt extract $(5 \mathrm{~g} / \mathrm{l})$ and the maximum productivity of Streptomyces diastaticus LC360811. Similarly, Bashir et al. (2012) found that glucose and yeast extract are the most suitable carbon and nitrogen sources, for the growth and production of the bioactive metabolites from Streptomyces PT1.

The results revealed that n-butanol extract exhibited the highest average inhibition zone (12) $\mathrm{mm}$ for $S$. diastaticus LC360811, with a maximum activity of $17 \mathrm{~mm}$ against Staphylococcus aureus. The n-butanol was reported the best solvent to extract antimicrobial compounds from Streptomyces sp. isolates (Torres et al., 2017), and it is the solvent of choice with antibacterial activities against both $S$. aureus and Candida albicans (Amin et al., 2016). Forar et al. (2007) referred to n-butanol as suitable for extraction of bioactive compounds from Streptomyces sp. In contrary, Vijayakumar (2012) observed that ethyl-acetate was the best solvent for the antimicrobial extract of the Streptomyces strain VPTS3-1 against $C$. albicans and Pseudomonas mirabilis with a maximum inhibitory zone of 20 and $19 \mathrm{~mm}$, respectively. Moreover, in the present study, 1L of butanol extract produced approximately $20 \mathrm{mg}$ sticky brown crude extract from $S$. diastaticus LC360811. This amount is considerably greater than that $(1 \mathrm{mg})$ produced from 1.5 L of culture broth (Mercy \& Krishnan, 2013).

TLC direct bioautography is a very sensitive assay that gives an accurate localization of active compounds (Balouiri et al., 2016). Lomascolo et al. (1999) stated that veratraldehyde is a natural aromatic food additive, and identifiedit from white rot basidiomycetes. The present study might be unique to classify veratraldehyde from marine actinomycetes, perform extraction, and purify this compound from marine Streptomyces sp. 
Lucera et al. (2014) reported that antimicrobials excreted from microbial sources find application in a number of food products such as milk, orange juice, and tomato juice, and in increasing the shelf life of chicken meat without changing the properties of the product. The purified veratraldehyde, isolated from $S$. diastaticus, increased the shelf life of fermented milk samples up to 21 days without any spoilage compared with untreated milk samples. Similarly, Onyango et al. (2014) reported that the incorporation of indigenous plants, Oleaeuropaea, in milk samples extended the shelf life of fresh milk for 4 days and that of fermented milk up to one month without spoilage. In addition, in the present study, purified veratraldehyde extracted from $S$. diastaticus increased the shelf life for more than 14 days for orange juice and pomegranate juice more than banana and guava juice, without any observed change in the smell. Additionally, Ali et al. (2016) reported that supernatant of Lactobacillus increased the shelf life of orange juice than apple and pomegranate juices by 14 and 21 days of storage.

In conclusion, $S$. diastaticus LC360811 proved to be a good candidate for the production of bioactive antimicrobial compounds with potential role in maintaining the quality of fresh juice and milk as a food additive. Further studies are currently recommended to evaluate other activities of this product.

\section{REFERENCES}

Aadhimani, J.; Madhusudhanan, K.; Saraswathi, M. and Arumugam, P. (2015). Screening and antimicrobial studies on bioactive compounds produced by marine actinomycetes. IJCBS, 2: 2349-2724.

Abad, M..J.; Bedoya, L.M. and Bermejo, P. (2011). Marine compounds and their antimicrobial activities. Science against microbial pathogens: communicating. Curr. Res. Technol. Adv., 2(1): 1293-1306.

Al-Askar, A.; Abdul-khair, W.M.; Rashad, Y.M.; Hafez, E.; Ghoneem, K.M. and Baka, Z.A. (2014). Streptomyces griseorubens E44G: A potent antagonist isolated from soil in Saudi Arabia. J. Pure Appl. Microbiol., 8(2): 221-230.

Ali, W.H.; Nibras, N.; Ali, M.H. and Rayim, S.A. (2016). Effect of some natural preservatives on some homemade fresh fruit juices. Adv. Environ. Biol., 10(3): 23-27.

Al-Sarrani, A.Q.M. and El-Naggar, M.Y. (2006). Application of Plackett-Burman factorial design to improve citrinin production in Monascus ruber batch cultures. Botan. Stud., 47(2): 167-174.

Amin, H.; Ashraf, K. and Khosrow, I. (2014). Streptomycetes: Characteristics and Their Antimicrobial Activities. Inter. J. Adv. Biol. Biomed. Res., 2(1): 63-75.

Amin, M.U.; Khurram, M.; Khan, T.A. and Iriti, M. (2016). Effects of Luteolin and Quercetin in Combination with Some Conventional Antibiotics against MethicillinResistant Staphylococcus aureus. Intern. J. Mol. Sc., 17(11): 1947. 
Anuradha, K.; Shravan, K.; Bhama, S. and Kishan, V. (2014). Fermentation, isolation, purification and characterization of an anti-tubercular antibiotic from Streptomyces luridus MTCC 4402. Indian J. Exp. Biol., 54(1): 1-12.

Arulappan, J.; Elumalai, S.; Perumal, D.; Sivaji, S. and Perumal, M. (2012). Detection of Antioxidant and Antimicrobial Activities in Marine Actinomycetes Isolated from Puducherry Coastal Region. J. Modern Biotechnol., 1(2): 63-69.

Attimarad, S.; Gaviraj, E.; Nagesh, C.; Kugaji, M. and Sutar, M. (2012). Screening, isolation and purification of antibiotic(S) from marine actinomycetes. Res. Article IJRAP, 3(3): 447-453.

Balouiri, M.; Moulay, S. and Saad, K. (2016). Methods for in vitro evaluating antimicrobial activity. J. Pharm. Anal., 6 (1): 71-79.

Bashir, Z.A.; Ahmad, A.; Nor, M.N. and Gires, U. (2012). Factors affecting bioactivity of secondary metabolites produced by Streptomyces sp. PT1 using Plackett-Burman design. Adv. Environ. Biol., 8(2): 1-10.

Braga, A.; Carlos, G. and Isabel, B. (2018). Generation of flavors and fragrances through biotransformation and de novo synthesis. Food Biop. Technol., 11(1): 22172228.

El-Moslamy, S.H.; Shehata, N.S.; Ahmed, W.R. and El-Naggar, M.Y. (2018). Statistical bioprocess strategies for bio-fabrication of nano-Ag from Streptomyces rectiviolaceus strain SMWN3.2 as a novel antimicrobial agent against hospital-acquired infectious pathogens. J. Pure Appl. Microbiol., 12(2): 439-458.

El-Naggar, M.Y.; Gohar, Y.M.; Barakat, K.M. and Aly, N.S. (2016). Physiological response, antibacterial activity, and cinnamaldehyde production by a marine Streptomyces chartreusis. J. Pure Appl. Microbiol., 10(3):1797-1808

El-Naggar, M.Y.; Ramadan, W. and El-Hamamsy, R.A. (2017). The application of mediated biosynthesized green silver nanoparticles by Streptomyces griseorubens in water treatment. J. Pure Appl. Microbiol., 11(2): 685-694.

Forar, L.R.; El-S.hafei, A.; Saker, M.; Cheikh, B. and Hocine, H. (2007). Screening, isolation and characterization of a novel antimicrobial producing actinomycete, Strain RAF10. Biotechnol., 6(1): 489-496.

Gebreyohannes, G.; Moges, F.; Samuel, S. and Nagappan, R. (2013). Isolation and characterization of potential antibiotic producing actinomycetes from water and sediments of Lake Tana, Ethiopia. Asian Pac. J. Trop. Biomed., 3(6): 426-435.

Hug, J.J.; Bader, C.D.; Remškar, M.; Cirnski K. and Müller R. (2018). Concepts and methods to access novel antibiotics from Actinomycetes. Antib., 44(7): 1-47.

Hunadanamra, S.; Akaracharanya, A. and Tanasupawat, S. (2013). Characterization and antimicrobial activity of Streptomyces strain from Thai mangrove soils. Intern. J. Bioass., 2(5): 775-779. 
Igbinosa, E.O.; Igelige, A.E.; Igbinosa, I.H.; Beshiru, A.; Odjadjare, E.E.; Ekhaise, F.O. and Oko, A.I. (2017). Isolation and characterization of antibacterial metabolites produced by Streptomyces species from Escravos River, Delta State, Nigeria. Trop. J. Nat. Prod. Res., 1(1): 22-31.

Ismaili, M. A.; Saidi, B.; Zahar, M. and Ezzaier, R. A.-H. (2016). Composition and microbial quality of raw camel milk produced in Morocco. J. Saudi Soc. Agricult. Sc., 18: 17-21.

Jose, P.A. and Jebakumar, S.R.D. (2013). Diverse actinomycetes from Indian coastal solar salterns - a resource for antimicrobial screening. J. Pure Appl. Microbiol., 7: 25692575.

Kaur, H.; Jemimah, G.O.; Vishal, S. and Daljit, S.A. (2015). Isolation, purification and characterization of novel antimicrobial compound 7-methoxy-2,2-dimethyl-4-octa-4', 6'-dienyl-2H-napthalene-1-one from Penicillium sp. and its cytotoxicity studies. AMB Express, 5(1): 40-54.

Kim, J.H.; Mahoney, N.; Chan, K.; Campbell, B.; Haff, R. and Stanker, L. (2014). Use of benzo analogs to enhance antimycotic activity of kresoxim methyl for control of aflatoxigenic fungal pathogens. Frontiers Microbial., 87(5): 1-12.

Lomascolo, A.; Stentelaire, C.; Asther, M. and Lesage-Meessen, L. (1999). Basidiomycetes as new biotechnological tools to generate natural aromatic flavours for the food industry. Trends Biotechnol., 17(7): 282-289.

Lucera, A.; Costa, C.; Conte, A. and Del Nobile M.A. (2014). Food applications of natural antimicrobial compounds. Front. Microbiol., 3: 287.

Manivasagan, P.; Kanga, K-H.; Sivakumarb, K. and Chance, E.C. (2014). Marine actinobacteria: An important source of bioactive natural products. Environ. Toxicol. Pharmacol., 38(1): 172-188.

Mercy, R.B. and Krishnan, K. (2013). Identification of antibacterial secondary metabolite from marine Streptomyces sp. VITBRK4 and its activity against drug resistant Gram positive bacteria. Inter. J. Drug Develop. Res., 5(4): 224-232.

Mohseni, M.; Norouzi, H.; Hamedi, J. and Roohi, A. (2013). Screening of antibacterial producing Actinomycetes from sediments of the Caspian Sea. Int. J. Mol. Cell Med., 2(2): 64-71.

Molleti, A. and Yadav, G. (2017). Green synthesis of veratraldehyde using potassium promoted lanthanum-magnesium mixed oxide catalyst. Org. Process Res. Develop., 21(7): 1012-1020.

Onyango, C.A.; Gakuya, L.W.; Mathooko, F.M.; Maina, J.M.; Nyaberi, M.O.; Makobe, M. and Mwaura, F. (2014). Preservative effect of various indigenous plants on fermented milk from Maasai community of Kajiado. J. Appl. Biosci. 73: 5935-5941.

Pandey, R. and Upadhyay, S. (2012). Food Additive. In Tech., pp. 1-30. 
Prashant, N.K.; Anupama, S. and Ganapati, D.Y. (2014). Synthesis and Biological Evaluation of Some novel Schiff's bases of veratraldehyde. Asian J Chem. Pharm. Res., 2(1): 65-68.

Priyadarshini, A.; Singdevsachan, S.K.; Tripathy, S.K.; Mohanta, Y.K.; Patra, J.K. and Sethi, B.K. (2016). Isolation and identification of Actinomycetes from Mangrove soil and extraction of secondary metabolites for antibacterial activity. British Biotechnol. J., 12(2): 1-13.

Rahman, M.A.; Islam, M.Z.; Anwar, M. and Islam, U. (2011). Antibacterial activities of Actinomycete isolates collected from soils of Rajshahi, Bangladesh. Biotechnol. Res. Inter., 1-6.

Rajendran, V.; Palanisamy, B.D.; Sathyaseelan, S.; Per, B. and Venkatesan, B. (2012). Optimization of resistomycin production purified from Streptomyces aurantiacus AAA5 using response surface methodology. J. Biochem. Tech., 3(4): 402-408.

Shetty, P.R.; Buddana, S.K.; Tatipamula, V. B. and Ahmad, J. (2014). Production of polypeptide antibiotic from Streptomyces parvulus and its antibacterial activity. Braz. J. Microbiol., 45(1): 303-312.

Singh, V.; Haque, S.; Niwas, R.; Srivastava, A.; Pasupuleti, M. and Tripathi, M. (2017). Strategies for fermentation medium optimization. Frontiers Microbiol., 7(1): 116.

Subramani, R. and Aalbersberg, W. (2012). Marine actinomycetes: An ongoing source of novel bioactive metabolites. Microbiological Research 167(2): 571-580.

Subramanian, D.; Kim, M.; Kim, D. and He, M. (2017). Isolation, Characterization, Antioxidant, Antimicrobial and Cytotoxic Effect of Marine Actinomycete, Streptomyces carpaticus MK-01, against Fish Pathogens. Braz. Arch. Biol. Technol., 60(1): 1-9.

Tamreihao, K.; Debananda, S.; Salam, N.; Elangbam, N.; Singh, S.; Reena, P., Herojeet, S.; Upendra, S. and Nongthomba, M. (2018). Biocontrol and plant growth promoting activities of Streptomyces corchorusii strain UCR3-16 and preparation of powder formulation for application as biofertilizer agents for rice plant. Microbiol. Res., 192(1): 260-270.

Thirumalairaj, J.; Shanmugasundaram, T.; Sivasankari, K.; Natarajaseenivasan, K. and Balagurunathan, M. (2008). Isolation, screening and charactrization of potent marine Streptomyces sp. PM105 against antibiotic resistant pathogens. Asian J. Pharm. Res., 8(2): 0974-2441.

Tiossi, R.; Miranda, M.A.; de Sousa, J.P.B. and Bastos, J.K. (2012). A Validated Reverse Phase HPLC Analytical Method for Quantitation of Glycoalkaloids in Solanum lycocarpum and Its Extracts. J. Anal. Meth. Chem., (3): 947836.

Torres, V.; Encinar, J.A.; López, M.H.; Sánchez, A.P.; Galiano, V.; Catalán, E.P. and Micol, V. (2017). An updated review on marine anticancer compounds: the use of virtual screening for the discovery of small-molecule cancer drugs. Molecules, 22(1037): 1-37. 
Vijayakumar, R.; $\quad$ Panneerselvam, K.; $\quad$ Muthukumar, C.; $\quad$ Thajuddin, N.; Panneerselvam, A. and Saravanamuthu, R. (2012). Optimization of Antimicrobial Production by a Marine Actinomycete Streptomyces afghaniensis VPTS3-1 Isolated from Palk Strait, East Coast of India. Ind. J. Microbiol., 52: 230-239.

Wagner, H.; Bladt, S. and Zgainski, E.M. (1984). Plant drug analysis. A thin layer chromatography altlas. Springer-Verlag. Berlin Heidelberg New York Tokyo, 309pp.

Ye, L.; Zhou, Q.; Liu, C.; Luo, X.; Na, G. and Xi, T. (2009). Identification and fermentation optimization of a marine-derived Streptomyces griseorubens with antitumor activity. Ind. J. Mar. Sc., 38(1): 14-21. 